Elsevier required licence: (C) <2017>. This manuscript version is made available under the CC-BY-NC-ND 4.0 license http://creativecommons.org/licenses/bync-nd/4.0/ 


\section{Manuscript Details}

Manuscript number

Title
JUIP_2016_20

Detailed water-use feedback: a review and proposed framework for program implementation

Full length article

Article type

\section{Abstract}

Smart water metering (SWM) introduces new opportunities to engage householders about water use based on detailed information. Water utilities must decide how to embrace these opportunities, but remain hesitant due to limited available experience and knowledge, which risks delaying the benefits of involving householders more fully in SWM and more sustainable water consumption. An implementation framework is developed outlining key elements in decision-making for detailed feedback programs by drawing on the literature and first-hand experiences of two feedback trials involving SWM. Existing approaches are reviewed and recommendations provided to advance more well-considered approaches and realise benefits regarding sustainable water use.

Keywords

Corresponding Author

Corresponding Author's

Institution

Order of Authors

Suggested reviewers smart metering; program implementation framework; water-use feedback.

Ariane Liu

University of Technology Sydney

Ariane Liu, Damien Giurco, Pierre Mukheibir, Stuart White

Joe Flynn, Cara Beal

\section{Submission Files Included in this PDF}

\section{File Name [File Type]}

Cover Letter.docx [Response to Reviewers]

JUP 2016-20 Smart water use jb2_AL.v1.docx [Manuscript File]

Research Highlights.docx [Highlights]

To view all the submission files, including those not included in the PDF, click on the manuscript title on your EVISE Homepage, then click 'Download zip file'. 
Dear Editor-in-Chief Janice Beecher,

Please find attached our revised paper now entitled "Detailed water-use feedback: a review and proposed framework for program implementation".

We have carefully addressed each of your edits and comments and updated the framework as recommended.

Many thanks again for your wonderfully helpful review of our work.

Kind regards,

Ariane Liu

Researcher

Institute for Sustainable Futures

University of Technology, Sydney

Tel.: +61 295144950

Mobile: +61 405728536

Fax.: +6129514 4941

Email: Ariane.Liu@uts.edu.au 


\section{Detailed water-use feedback: a review and proposed framework for program implementation}

Ariane Liu*, Damien Giurco, Pierre Mukheibir, Stuart White

University of Technology Sydney, Institute for Sustainable Futures, NSW, Australia

* Corresponding author. Institute for Sustainable Futures, University of Technology Sydney, P.O. Box 123

Broadway, New South Wales 2007, Australia. Tel.: +61 29514 4972. Fax.: +61295144941.

Emails: ariane.liu@uts.edu.au (A. Liu),damien.giurco@uts.edu.au (D. Giurco),

pierre.mukheibir@uts.edu.au (P.Mukheibir), stuart.white@uts.edu.au (S.White).

\section{Research highlights}

- Smart metering presents new opportunities to engage householders about water use.

- Experiences from two household water-use feedback trials are structured.

- The literature on smart metering for water and feedback is reviewed.

- A program implementation framework for detailed water-use feedback is developed.

- Water utilities can target efforts that contribute to sustainable water usage. 


\title{
Detailed water-use feedback: a review and proposed framework for program implementation
}

\begin{abstract}
Smart water metering (SWM) introduces new opportunities to engage householders about water use based on detailed information. Water utilities must decide how to embrace these opportunities, but remain hesitant due to limited available experience and knowledge, which risks delaying the benefits of involving householders more fully in SWM and more sustainable water consumption. An implementation framework is developed outlining key elements in decision-making for detailed feedback programs by drawing on the literature and first-hand experiences of two feedback trials involving SWM. Existing approaches are reviewed and recommendations provided to advance more well-considered approaches and realise benefits regarding sustainable water use.
\end{abstract}

\section{Keywords}

Smart metering; program implementation framework; water-use feedback. 


\section{Introduction}

\subsection{Smart metering: an opportunity for customer involvement yet a challenge for water utilities}

Smart water metering (SWM) and advanced information and communication technologies in the digital age present new opportunities for customers to engage based on detailed and customised information about water usage and efficiency measures (Boyle et al., 2013; Liu et al., 2013). Water utilities, however, face the challenge of deciding how to embrace these new opportunities.

Water utilities demonstrate growing interest in the availability of new SWM technologies through active participation in SWM-related conferences and meetings. According to recent surveys conducted in the US (Neptune Technology Group, 2015) and Australasia (Beal and Flynn, 2015), water utilities expressed significant plans for increasing their SWM-related activities. Interest in expanding SWM to achieve additional customer benefits, including the provision of more detailed consumption feedback (i.e. customised information on how much water is used, when, and how) is also growing. In the US, $50 \%$ of surveyed utilities reported the wider opportunity for "improved customer service" as one of the main benefits of SWM (Neptune Technology Group, 2015). However, this interest in detailed feedback still lags significantly behind the wider interest in SWM. In the Australasia region, only $12 \%$ of surveyed utilities engaging in SWM projects involved "information sharing with customers" (Beal and Flynn, 2015).

Beyond the concern regarding the return on investment, important barriers to SWM relate to the current lack of information and experience. According to Beal and Flynn (2015), a key challenge to planning SWM projects included "limited industry knowledge from previous smart metering projects". Also, regarding implementing SWM projects, "limited industry experience in rolling out smart metering" was identified as the greatest challenge (Beal and Flynn, 2015). These challenges apply all the more so to detailed water-use feedback programs enabled via SWM, for which there is still less industry knowledge and experience from which to learn.

In practical terms, water utilities have to grapple with many issues that surround the design, implementation, and evaluation of detailed water-use feedback programs and no general guidelines or framework are currently available. In addition, there is no overview of the studies that have been conducted to date, and limited documentation exists concerning how projects were designed and what considerations were taken into account. As a result, water utilities lack a comprehensive understanding of how to provide detailed water-use feedback with SWM. Given this lack of knowledge about relevant issues and approaches, together with the need for clearer business-case evidence, it perhaps is unsurprising that many water utilities currently remain hesitant about SWM implementations involving detailed household water-use feedback programs.

Inaction by water utilities regarding detailed water-use feedback will limit, or at least delay, the role for householders that are willing to engage more actively in household water management and the new opportunities afforded by SWM in the digital age (Liu et al., in press). Active engagement of householders regarding their water use nevertheless remains a potentially important opportunity for promoting sustainable usage and resource management, and various trials have demonstrated water-savings over longer periods of time (e.g. Davies et al., 2014; Fielding et al., 2013). While inaction risks missed opportunities, uninformed action may also result in disappointing outcomes. For example, water utilities risk incurring large sunk investment costs and technological 'lock-in' (obsolescence) to approaches that yield 
insignificant engagement and impacts. There is thus an important need to identify the key issues for consideration and to review and summarise the state of the art in providing detailed water-use feedback, as well as to offer recommendations based on what is known, along with suggestions for addressing the unknowns.

\subsection{Research aims}

This research builds on collaboration between the Institute for Sustainable Futures (ISF) at the University of Technology Sydney and MidCoast Water (MCW) in New South Wales (NSW) and Griffith University in Queensland (QLD), Australia (2012-2015), which through two distinct trials, explored the role for detailed water-use feedback via SWM to promote behavioural changes toward more sustainable urban water usage. This paper aims specifically to draw out key elements in decision-making for detailed feedback enabled via SWM based on the in-depth experiences of the ISF-MCW research along with a review of the existing literature. ${ }^{1}$

The overarching aim of this paper is to develop an implementation framework that outlines key decision elements to provide practical guidance to water utilities considering detailed customer water-use feedback. The framework can add significant value by bringing the various considerations together at a conceptual and strategic level, particularly at a time when detailed water-use feedback programs are still relatively few in number and guidance to water utilities is much needed. An implementation framework can help utilities plan their own approaches and evaluate the growing number of offerings by managed service providers. While new issues may emerge over time, the present framework represents an important contribution by mapping out key issues identified thus far and can therefore serve as a comprehensive foundation upon which future work can eventually build. The additional discussion of the framework in relation to existing practice further aims to provide a comprehensive and up-to-date overview, with recommendations for research and practice to advance implementations to promote more sustainable water resource consumption. The research thus aims to address important knowledge gaps concerning (i) the issues water utilities should consider when undertaking detailed water-use feedback programs; (ii) the current state of detailed water-use feedback; and (iii) research needs.

In order to justify an investment by water utilities, the cost-effectiveness of detailed water-use feedback would require a detailed assessment, including against alternative approaches to communicating and managing water-use. This is identified as a future research direction, which goes beyond the scope of this analysis and review.

The rest of the paper proceeds as follows. Section 2 describes the research study methods. Section 3 presents the implementation framework for detailed water-use feedback programs enabled via SWM. Section 4 discusses the framework in relation to previous literature, provides recommendations and identifies directions for future research. Section 5 closes by summarising the implications of the research.

\section{Methods}

\subsection{Research approach}

\footnotetext{
1 The ability to draw on first-hand experiences through continuous full-time involvement by the first author as a doctoral researcher throughout the three-year ISF-MCW research program is a distinctive feature of this research, offering detailed insight into the many decisions taken, alternatives, practical challenges, and limitations.
} 
The implementation framework, which provides a detailed overview of the key considerations for the design, implementation, and evaluation of water-use feedback programs in conjunction with SWM, was developed following the process shown in Fig. 1.

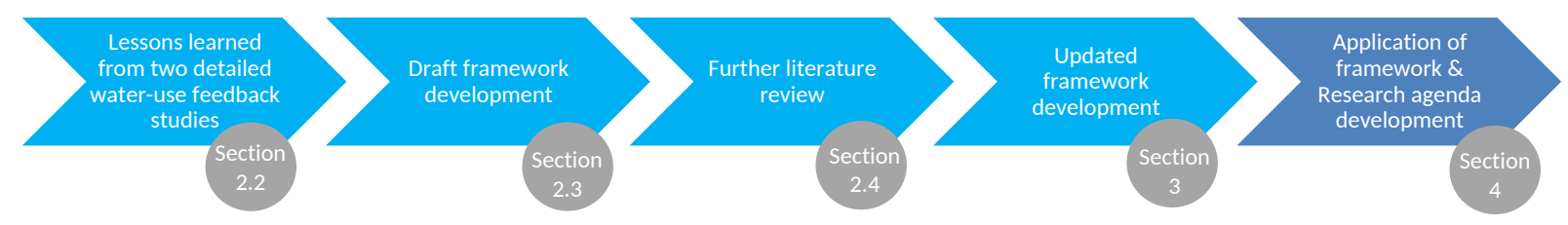

Fig. 1 Implementation framework development process.

A review of experiences from our two recent feedback studies involving SWM in NSW, Australia, was used as the starting point for development of a draft of the implementation framework. ${ }^{2}$ Our revisiting of the decisions taken and lessons learned was enhanced by a review of the literature on detailed water-use feedback to capitalise on additionally available experiences and increase the validity of the framework.

\subsection{Two recent detailed feedback studies}

Both feedback studies were located within MCW's service area in NSW, Australia, about 320 kilometres northeast of Sydney. The 'Home Water Update' (paper reports) study $(\mathrm{N}=68)$, involved the provision of detailed end-use feedback to household customers via paper-based reports and was undertaken in two small coastal towns, Tea Gardens and Hawks Nest, which have a combined population of 3,550 (Profile.ID, 2011a). The 'My Home Our Water' (online portal) study ( $N=120)$, involved access to a custom-built online portal providing water-use feedback in near real-time to households in Greater Taree, which has a total population of 46,540 spread across a number of towns and localities (Profile.ID, 2011b). Both studies adopted a mixed methods research approach and involved an intervention and a control group, with smart water meter consumption data (logged at one minute intervals) and surveys and/or interviews used to assess impacts.

Fig. 2 shows a sample 'Home Water Update' paper report and Fig. 3 shows screenshots of the 'My Home Our Water' online portal, which serve as examples of recent forms of detailed household water-use feedback enabled via SWM. The interested reader is also referred to Liu et al. $(2016,2015)$ for more detailed descriptions of the methods and results of the 'Home Water Updates' (paper reports) study; and to Liu et al. (2014) regarding the 'My Home Our Water' (online portal) study.

2 The first author's 'hands-on' involvement during all stages of both studies (i.e. from design to implementation to evaluation) resulted in rich exposure to the issues and a solid foundation for meeting the present research objectives. 


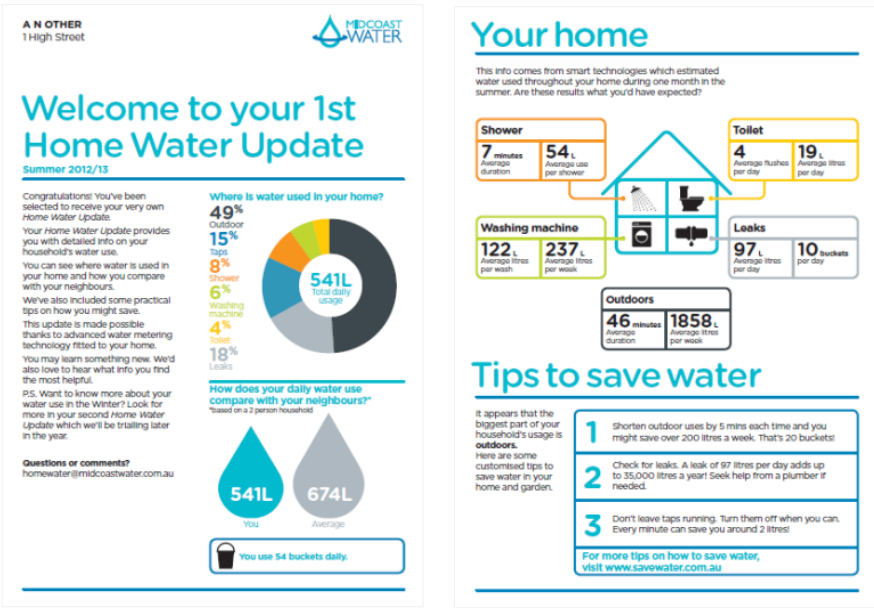

Fig. 2 Example of the 'Home Water Update' intervention medium - front and reverse sides.
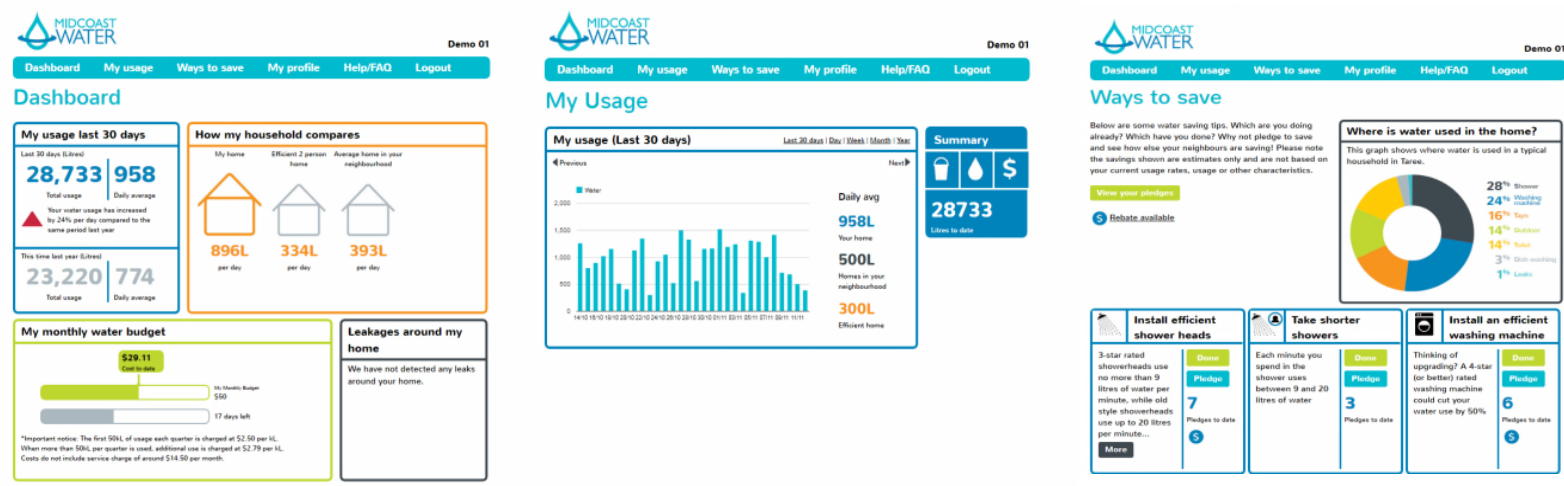

Fig. 3 'My Home Our Water' online portal - Dashboard, My Usage, and Ways to Save screens

The experiences and lessons in decision-making drawn from the two cases helped to structure the research at hand. For example, underlying issues were noted relating to who the subjects were, how they were selected, how many there were, what their characteristics were, and so on. One finding was that the 'Home Water Update' study's moderate sample size may not have been large enough to detect statistically significant impacts (Liu et al., 2016). Therefore, the question of sample size, its representativeness, and the conclusions that could be drawn were noted for inclusion in the draft framework. Continuing to the other defining aspects of the studies, in turn, helped to identify additionally relevant considerations for detailed feedback programs.

\subsection{Implementation framework development}

The program implementation framework was developed by identifying defining issues and elements to decision-making encountered during the various phases of our two research studies. These considerations were subsequently organised according to whether they related to the 'Why', 'When', 'Who' and 'What' of detailed water-use feedback program implementation. These guiding questions have been applied to 
organise an issue in a variety of other fields including in the social and medical sciences literature (Morris and Teevan, 2009; Sherrod et al., 2002), but not to the design of detailed water-use feedback programs.

We structured the analysis of our case experiences around these core questions. The question of 'Why' was adopted as concerning the driver(s) or motivation for a water utility to introduce detailed water-use feedback via SWM. 'When' referred to issues surrounding timing. 'Who' referred to the target audience and the means for its selection, as well as its location. Finally, 'What' was taken to refer to the design of the feedback and the adopted approach as well as the adopted means for providing the feedback. It became apparent during this work that these questions were particularly suited to identifying the practical considerations related to implementing a feedback program.

Other themes identified as relevant, but not specifically related to one of the four core questions, were noted down for separate organisation later in the framework. These items were later grouped as either strategic or evaluative considerations that fell outside of the more practical issues initially identified. The strategic considerations were further organised into four categories: 'Tactic', 'Technology', 'Theory of change' and 'Resources'. The evaluative considerations were further organised into three categories: 'Data collection', 'Analysis' or 'Knowledge sharing'.

\subsection{Literature review}

The results of our literature review and analysis are provided in the Appendix tables. ${ }^{3}$ Table 1 shows an overview of research studies/implementations organised according to the four practical questions (i.e. 'Why', 'When', 'Who' and 'What'). Table 2 shows the literature according to the strategic and evaluative considerations. Table 3 shows a detailed overview of information content by study.

To expand the scope of the academic literature review, the applied and grey literature was sourced via web searches. This search yielded various water utility reports and more general water industry-wide reports as well as online industry magazines and other news reports, which led to the identification of additional studies and experiences using detailed water-use feedback via SWM.

We found that most reports of detailed water-use feedback studies focused on presenting the particular approach adopted, which could inform the practical questions of 'When', 'Who', 'What' and to a lesser extent the 'Why'. ${ }^{4}$ Many of the choices, possibly a function of the research or program designs, however, were not put into perspective by, for example, discussing why alternative approaches might have been rejected. Left undescribed, it is unclear whether or not these issues were considered, and with which level of detail. By comparing and contrasting different approaches across the literature, it was possible to identify the alternative design options and considerations and to establish strategic-level questions and broader

\footnotetext{
${ }^{3}$ The literature review commenced with searches of a number of databases (Elsevier Science Direct, Taylor and Francis Online, IEEE, and Google Scholar) using pre-defined keywords relating to SWM, SWM trials and implementations and the provision of detailed water-use feedback to householders. Combinations of keywords were used including: "smart meter", "smart water meter", "feedback", "information", "water consumption", "household", "residential", "intervention". This search yielded reports of detailed feedback studies in high-quality international peer-reviewed journal articles.
}

${ }^{4}$ This observation is important and highlights the need for further research into the business case and economics (i.e. costs relative to benefits) of detailed water-use feedback enabled via SWM. 
considerations for inclusion in the framework. The literature review also helped us identify broader considerations, including research gaps in feedback strategies.

\section{Implementation framework for detailed water-use feedback enabled via SWM}

Based on our research, Fig. 4 graphically presents our program implementation framework, highlighting key considerations in the design of detailed water-use feedback programs involving SWM. The implementation framework is presented as four embedded concentric circles for heuristic purposes. The order chosen here places the objective at the centre (detailed feedback for sustainable water-use); with strategic considerations in the next circle (theory of change, tactic, resources, and technology); and more practical design considerations, concerning the 'Why', 'When', 'Who' and 'What' questions in the next wider circle; finishing with overarching evaluative issues concerning data collection, analysis and the dissemination of results in the outermost circle. Each of the layers and categories in the framework are discussed in more detail in the following section.

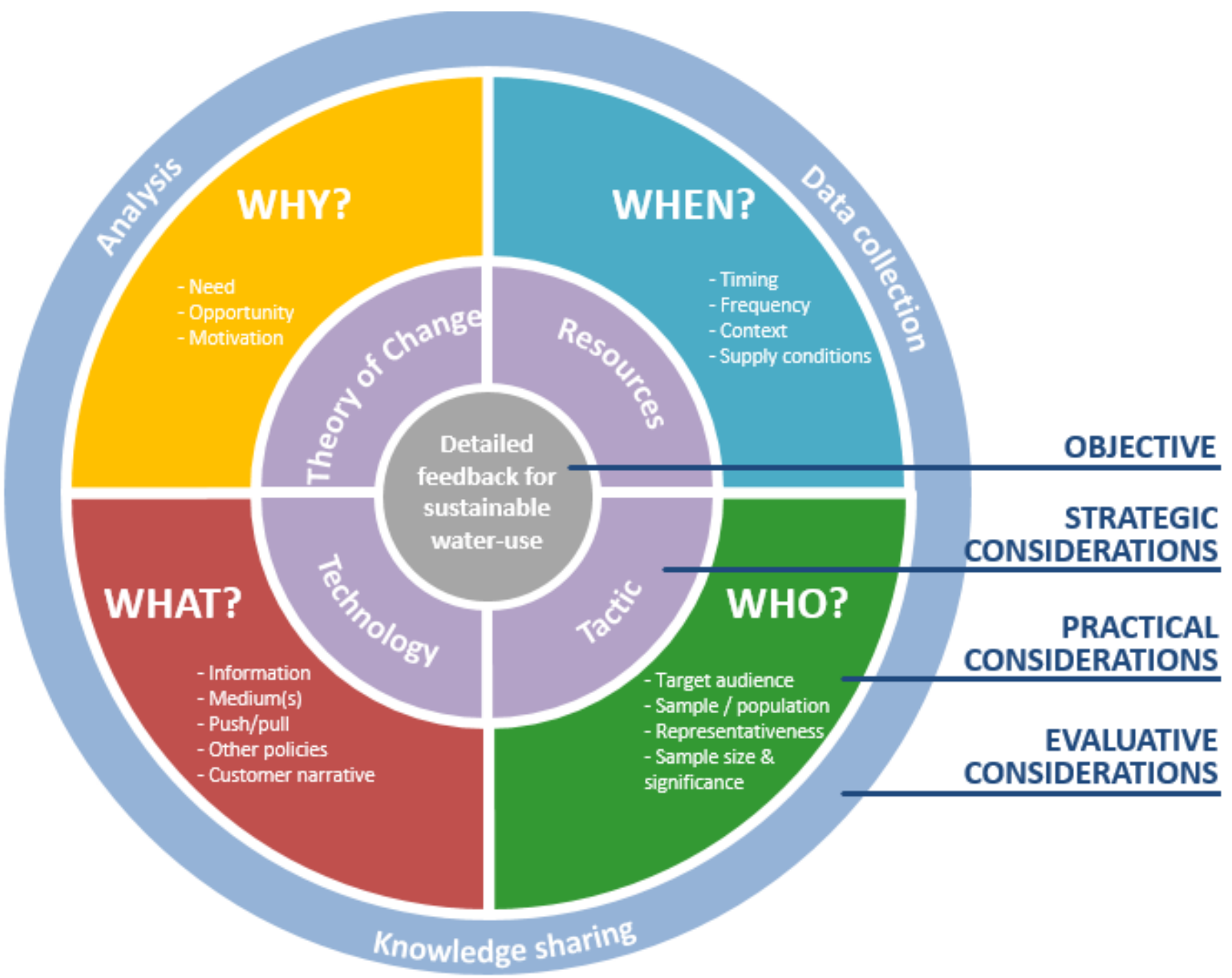

Fig. 4 Program implementation framework for detailed water-use feedback programs involving SWM 


\section{Current approaches and recommendations based on the framework}

This section presents the various elements of the program implementation framework as developed through our research and literature review. The section aims to provide an overview of the current state of work related to detailed water-use feedback as well as practical advice to guide water utilities to advance SWM and detailed feedback programs in the pursuit of sustainable urban water management. This analysis also signals areas in need of further research. While the business case is not the focus of this work, the framework elements introduced below should also be integral to a detailed cost-benefit analysis of detailed water-use feedback via SWM.

\subsection{Objective}

At the centre of the program implementation framework, the objective of 'detailed feedback for sustainable water use' is placed. This objective derives from a desire to provide detailed water-use feedback in conjunction with SWM deployment in a manner that aligns with the pursuit of sustainable urban water management.

\subsection{Strategic considerations}

The second innermost, strategic level circle includes the 'Theory of change', 'Tactic', 'Technology' and 'Resources'. Here, 'Theory of change' refers to the underlying beliefs about the relationships between actions (e.g. information provision) and targeted outcomes (e.g. water conservation behaviours). 'Resources' refers to the human capital, time commitment, and financial resources as well as budgetary and other constraints. 'Tactic' refers to the approach to be taken in order to reach the goals and objectives (e.g. a trial versus full-scale roll-out). Finally, 'Technology' refers to the SWM technology, including the metering device, communications between the device and the utility's system, and technologies required to produce customer water-use feedback.

A 'Theory of change' concerns the question of what change does the water utility want to bring about and what model is most appropriate in this context. This issue clearly relates to the practical consideration of 'Why', discussed in section 4.3.1 below. Most previous work tends to align broadly with the rational 'information-deficit' model (Burgess et al., 1998), which suggests that customer feedback can address gaps in customer knowledge and awareness and promote water-saving behaviours. Other relevant theories of behaviour change include Ajzen's theory of planned behaviour (Fielding et al., 2013) and community based social marketing (Anda et al., 2013). While it is not suggested that water utilities should be driven by theory alone, the provision of detailed water-use feedback in pursuit of goals has theoretical underpinnings.

Regarding 'Resources', funding of SWM projects is obviously important. While many water utilities have fully funded their wider SWM projects, external funding contributions (especially funding via federal government grants) have provided important support (see Beal and Flynn, 2015), including for much of the current activity in the area of detailed feedback. Utility workforce skills are another important resource in feedback implementations, and for this, many projects have involved university partnerships to secure additional human capital and ensure robust approaches to evaluation research (e.g. Britton et al., 2013; Fielding et al., 2013).

In terms of the 'Tactic', approaches differ regarding whether projects begin with a pilot, or with the plan for a full-scale implementation; and whether water utilities have targeted a more 'in-house' solution or opted for an outsourced, 'managed service'. Most research studies have involved SWM and feedback pilot projects. 
Some have also been opportunistic trials, whereby a need to replace an existing fleet of water meters offered the occasion to trial smart meters (Beal and Flynn, 2015). The role of a strong champion within water utilities favouring their adoption also appears to be a key factor, as was also the case with the two trials with MCW.

Regarding 'Technology', approaches vary according to the type of SWM, data capture, storage, transmission, and customer communications. In most cases, water utilities have first adopted a particular form of SWM, to which processes of providing feedback have been subsequently added. However, some have taken a more integrated approach, such as Mackay Regional Council (2015), by developing the feedback mechanism (an online portal) in conjunction with their SWM solution. Planning an approach at the start can help ensure suitable SWM technologies are implemented to support feedback (e.g. targeted speed, frequency and resolution) (Liu et al., in press). The authors note that in-house approaches may grant water utilities greater control and flexibility over feedback, at least with the initial design, but suggest that any commitment, including to an outsourced service offering, might benefit from negotiated flexibility for adaptations. This flexibility would allow utilities to develop approaches as new insights emerge on better ways to present feedback and to promote customer involvement (for example, to go beyond the observed participation rate of around 30\% in Erickson et al. (2012) and Liu et al. (2014)). In all cases, water utilities must be prepared for data communication issues, including with signal strength, and plan how to address them in advance since this was a recurring theme in recent research (e.g. Doolan, 2010).

\subsection{Practical considerations}

The next layer of the circle is dedicated to specific practical requirements of detailed water-use feedback programs. Here, the 'Why' element considers the water utility's needs and motivations for introducing detailed feedback, and how the SWM opportunity might satisfy these, i.e. "what's in it for them?" The 'When' element refers to the timing of feedback, its frequency and duration as well as the context and water supply conditions (e.g. normal supply or scarcity as during droughts). The 'Who' element requires identification of the target audience, whether population wide or targeting specific segments. Regarding sampling representativeness, sample size, and statistical significance all require consideration. The 'What' segment refers to the information feedback; the communication medium; who is directing the approach; how the information-feedback will relate to other policies (e.g., water demand management, rebates, pricing etc.); and the customer narrative to be used.

\subsubsection{Why}

SWM has many potential advantages for water utility resource and infrastructure planning and operational management, including automated meter reads and possibilities for improved network monitoring and management through increased data availability (Boyle et al., 2013). A logical next step for utilities is to more directly extend the benefits of SWM to customers, including householders, by providing them with access to detailed water-use information created and engaging them more actively in water management.

While SWM affords all water utilities with new opportunities and challenges, each circumstance is unique. Therefore, the main 'Why' for embracing the SWM and particularly detailed water-use feedback could vary, at least initially. For example, water utilities under water stress may face a more urgent need to reduce water demand to defer capital expenditures and avoid a costly supply augmentation, so programs to induce greater household water conservation could be more appealing (Turner et al., 2010). 
An alternative motivation for introducing detailed feedback could be the availability of funding resources, either internally or through government incentive programs and support (see Beal and Flynn, 2015). Another possible motivation concerns the 'reputational benefits' that many be conferred by establishing oneself as a leader or 'best-in-class' among water utilities through innovative customer engagement or a sustainability strategy (Young and Mackres, 2013), which could promote the standing of the water utility both with its customers and within the water industry.

Each water utility faces different needs, and so to do their customers. Detailed feedback could be linked to the needs of certain customer segments (e.g. to specifically target high water users or hardship customers struggling to pay their water bills) since detailed water-use feedback has been found to improve water literacy by reducing the discrepancy between actual and perceived water consumption (Beal et al., 2013).

\subsubsection{When}

Regarding 'When' to provide detailed water-use feedback, the issues of timing, frequency, and context are particularly relevant. A difference exists whether targeting efficient water use (i.e. using the same amount of water to perform the same function) or conservation (i.e. using less water).

Previous research has shown that water-savings achieved through detailed feedback can change over time and diminish when feedback ceases (e.g. Fielding et al., 2013). We further found that savings effects are linked to specific acts of engagement, such as logging on to an online feedback portal. Therefore, the timing and continuity of feedback are important.

Regarding context, there may be specific conditions under which special conservation efforts may be required, such as under supply constraints (in which case the question of 'When' will be closely linked to 'Why'). In times of drought, householders could be encouraged via a campaign to log on to view their consumption information online or mailed end-use consumption reports to advise them about specific water-saving opportunities. These approaches have led to both water-saving behaviours and investments in more water-efficient appliances even under normal supply conditions. However, such approaches would require water utilities to plan ahead and have the SWM and feedback infrastructure in place in order to be 'drought-ready' and thus able to achieve an immediate response. Therefore, water utilities should already include plans for detailed water-use feedback when planning SWM implementations (Liu et al., in press) and not limit feedback opportunities when selecting their SWM technology (Liu et al., 2016).

\subsubsection{Who}

The target audience of detailed water-use feedback should be considered both for feedback trials and full program implementation. If provision is not (initially) population wide, then sample selection is relevant. Sample selection criteria in a customised approach relates to the objectives (the 'Why') if particular segments are targeted (e.g., high-volume users, hardship customers, or properties with leaks) as well as locational considerations.

'Opt-in' approaches risk sample self-selection bias. If a trial is to be conducted first, with the intention of full roll-out later, then scalability should be ensured via selection of a representative sample for the trial. 'Optout' approaches have the advantage of first providing the opportunity to all customers; however, depending on 'opt-out' rates this may result in important losses in participation as well as sample bias. Sample size also has implications for evaluation and tests to detect significant differences in water consumption (either preversus post-intervention; or against a control group), as raised in Liu et al. (2016). The concept of sustainable 
urban water management may argue for all households to eventually receive detailed water-use feedback from their water utilities (Liu et al., in press). However, research on the costs, benefits, and impacts of different approaches to providing detailed water-use feedback on a system-wide basis remains very limited.

Customer information privacy is an issue is a potential concern with SWM and the gathering of detailed water consumption data (Giurco et al., 2010). This issue is directly relevant when considering to whom feedback will be provided. Due to privacy concerns, some householders may oppose being fitted with a smart meter. In the UK, SWM can be mandated by water utilities in areas of water stress, including the imposition of maximum water charges to any households that refuse an installation. This approach may motivate households to accept SWM. If not, refusal could mean no feedback. Based on currently available information, it is unclear what share of the population might be opposed to SWM installation.

\subsubsection{What}

SWM creates a variety of options for the presentation of detailed water-use feedback information to householders. An important finding in evaluating these options in Liu et al. (2015) was that a 'one-size-fitsall' approach is unlikely to achieve optimal benefits in view of the variations in customer preferences for feedback; a variety of approaches and customer segmentation were recommended.

Different approaches carry different relative advantages, with implications for program reach, access, content, customisation, interactivity, and specificity of feedback, which ultimately shape customer impacts. For example, online water-use feedback portal mediums have achieved usage rates of around 30\% (Erickson et al., 2012; Liu et al., 2014). Therefore, rather than simply offering one option, alternative options or a combination thereof may achieve greater customer involvement and benefits. For example, WaterSmart Software in San Francisco, California, now offers both online and paper-based feedback (WaterSmart, 2014). A combination of 'push' and 'pull' approaches can also be used. 'Push' refers to communications directed or timed by water utilities (e.g. campaigns), whereas 'pull' refers to more customer driven access (e.g. by logging on to an online water-use feedback portal). For example, through an online portal, customers can access 'pull' information at their convenience, whereas through various campaigns or alerts, feedback can be 'pushed' out to customers by the utility. We recommend that water utilities aim to retain a balance to 'push' information according to supply and demand needs, particularly in situations of water stress, rather than exclusively limiting feedback to customer initiative.

Opportunities also exist to combine feedback with other policy tools. While most previous studies and implementations have focused on information feedback, incentives have also been offered in parallel. Examples include $\$ 100$ rebates to assist with the costs of leak repairs (Britton et al., 2013); and competitions (Erickson et al., 2012; Wetherall, 2008) offering prize incentives for householders to act upon water-use feedback. While both time-of-use and seasonal pricing have also been discussed in the water sector, these have not yet been widely field-trialled in conjunction with SWM and feedback.

Finally, attention must be given to the narrative, story, or message to be communicated to householders when providing detailed water-use feedback. Research suggests experimentations with alternative message framing as this may influence outcomes (Fielding et al., 2013; Liu et al., 2015).

\subsection{Evaluative considerations}


The outer layer of the framework refers to evaluative considerations, which must be managed throughout the implementation of detailed water-use feedback programs. These are categorised here as considerations of 'Data collection', 'Analysis' and 'Knowledge sharing'.

\subsubsection{Data collection}

The chosen resolution of data as well as the means for its transmission, analysis, and communication will shape the options for detailed water-use feedback. Currently, for water end-use analysis, consumption data collected at a minimum of one minute intervals is required, whereas leak detection is based on an assessment of night flows using hourly data. Although higher resolution data offers greater options for detailed feedback, it also requires additional software and (currently) significant time for manual disaggregation. Medium-resolution data (e.g. hourly) has been proposed as an option for indicating wateruse patterns to householders in terms of when most water is used according to the period of the day or season (Cardell-Oliver, 2013). Naturally, the insights and advice this can provide are less specific than with higher resolution data disaggregated at end-use levels. Research into the impacts of feedback associated with medium resolution data beyond leak alerts has yet to be conducted. We recommend that water utilities implementing SWM maintain flexibility to adjust the logging interval as has also been required in previous trials, albeit in response to communication issues (Doolan, 2010).

\subsubsection{Analysis}

Analysis is critical to understanding the impacts of detailed water-use feedback programs and measuring the extent to which established goals are met. An analysis of water consumption data before and after feedback is likely to be the most important component of a quantitative evaluation. A variety of statistical approaches have been used, including comparisons of means, and usually against a control group. While SWM data has usually been analysed, quarterly billing data collected via a conventional meter has in some cases been used to assess long-term usage patterns (Davies et al., 2014). Comparing conventional meter records pre- and post-intervention can be used when baseline SWM data are not available through billing records. Ideally, however, a baseline of consumption data should be collected via SWM prior to the provision of detailed feedback in order for a more accurate assessment of interventions, as in the MHOW online portal study. The optimal duration of a baseline measurement period has not been established, with current practice varying from no baseline, to just a few weeks to more than one year (which can be used to capture seasonality). The choice may also depend on the 'why' of introducing feedback in the first place.

In addition to SWM data, water utilities may also want to collect other forms of data for program evaluation purposes. Current approaches have involved householder surveys and interviews. Alternatively, focus groups could be also used. These additional evaluation methods, including qualitative assessments, can be used to identify opportunities for program improvements.

\subsubsection{Knowledge sharing}

SWM and detailed water-use feedback projects have largely been conducted independently, with limited information sharing regarding projects, status, approach, decisions, and recommendations. However, recent projects such as DAIAD (Athanasiou et al., 2014) and iWIDGET (Ganhao et al., 2015), represent more collaborative approaches between researchers and a few water utilities in Europe. A more coordinated approach to project trials and implementations could maximise the opportunity for shared learning and associated benefits (Liu et al., in press).

Based on the available literature on SWM implementation, we note that there is much activity for which little knowledge or findings have been disseminated publicly. Wider reporting represents an important 
underexploited opportunity for the water industry to improve knowledge and understanding, including of actual effectiveness, and to build and improve upon existing practice, rather than 'doing more of the same'.

The formation of some local research and industry networks can help facilitate information sharing. However, sharing on a more global scale is required to more fully understand programs, progress, and new insights as they emerge. At the same time, international experiences should be conveyed in a manner that is transferrable and relevant to local contexts.

\subsection{Overall recommendations and directions for future research}

This paper argues that water utilities should be well informed of the options for implementing detailed water-use feedback programs and have a clear understanding of the relative merits and implications of alternative approaches. An understanding of previous and current SWM feedback projects is important. Available knowledge also should be harnessed and continually developed to optimise impacts in terms of customer involvement, water-use awareness, and water consumption. Water utilities should aim to integrate, within their vision for SWM, the provision of detailed water-use feedback that supports sustainable urban water management.

Based on our proposed framework, the following gaps in the literature and practice suggest priorities for future research:

- Regarding 'Why', an investigation of as yet unexplored motivations for detailed household water-use feedback programs, such as targeting low-income groups and customers in arrears with their bill payments; or with the introduction of new tariffs.

- Regarding 'When', an investigation of the provision of detailed water-use feedback (e.g. high-volume uses) in contexts of water stress (such as droughts) to explore opportunities for greater collaboration between water utilities and customers to overcome scarcity.

- Regarding 'Who', an investigation of the impacts of the provision of detailed water-use feedback for an entire population (rather than only with self-selected trial participants). This research could be conducted opportunistically in conjunction with a new smart meter roll-out or upgrade across a district metered area. Specifically targeted audiences also warrant further explorations, which relates to the 'Why' of feedback, discussed above.

- Regarding 'What', an investigation of detailed water-use feedback in conjunction with customer segmentation, such as according to householder preferences, possibly including other forms of consumption feedback (e.g. related to household energy use). While designed for the consideration of detailed water-use feedback in conjunction with SWM, we suggest that our framework is also applicable to energy-use feedback.

Investigating these research topics would help to further the understanding of the role of detailed water-use feedback and help optimise its beneficial impacts.

\section{Conclusion}

A framework for understanding detailed water-use feedback programs in conjunction with SWM was developed based on first-hand experiences with two household trials. The framework presents a comprehensive overview of key considerations for the design, implementation, and evaluation of water-use feedback programs in conjunction with SWM and serves as an overarching guide to water industry practitioners and researchers. The framework was used to review current approaches and provide 
recommendations based on our research as well as the literature. This research will help foster more wellconsidered approaches and implementation, furthering opportunities for advancing knowledge and extending the potential benefits of SWM to households by engaging them in sustainable urban water management.

\section{Acknowledgements}

This research builds on work conducted within a larger program of collaborative research between the Institute for Sustainable Futures at the University of Technology Sydney and MidCoast Water in New South Wales (NSW) and Griffith University in Queensland (QLD), Australia (2012-2015) which was supported under the Australian Research Council's Linkage Projects funding scheme (LP110200767). Special thanks are due to Editor-in-Chief Janice Beecher and the anonymous reviewer for their very helpful and detailed comments on the paper.

\section{References}

Anda, M., Brennan, J., Paskett, E., 2013. Combining smart metering infrastructure and a behavioural change program for residential water efficiency: results of a trial in the southern suburbs of Perth, Western Australia. Water J. Aust. Water Assoc. 40, 66-72.

Athanasiou, S., Staake, T., Stiefmeier, T., Sartorius, C., Tompkins, J., Lytras, E., 2014. DAIAD: Open water monitoring. Procedia Eng. 89, 1044-1049. doi:10.1016/j.proeng.2014.11.223.

Beal, C.D., Flynn, J., 2015. Toward the digital water age: Survey and case studies of Australian water utility smart-metering programs. Util. Policy 32, 29-37. doi:10.1016/j.jup.2014.12.006.

Beal, C.D., Stewart, R.A., Fielding, K., 2013. A novel mixed method smart metering approach to reconciling differences between perceived and actual residential end use water consumption. J. Clean. Prod. 60, 116-128. doi:10.1016/j.jclepro.2011.09.007.

Boyle, T., Giurco, D., Mukheibir, P., Liu, A., Moy, C., White, S., Stewart, R., 2013. Intelligent metering for urban water: a review. Water 5, 1052-1081. doi:10.3390/w5031052.

Britton, T.C., Stewart, R.A., O'Halloran, K.R., 2013. Smart metering: enabler for rapid and effective post meter leakage identification and water loss management. J. Clean. Prod. 54, 166-176. doi:10.1016/j.jclepro.2013.05.018.

Burgess, J., Harrison, C., Filius, P., 1998. Environmental communication and the cultural politics of environmental citizenship. Environ. Plan. A 30, 1445-1460. doi:10.1068/a301445.

Cardell-Oliver, R., 2013. Water use signature patterns for analyzing household consumption using medium resolution meter data. Water Resour. Res. 49, WR014458. doi:10.1002/2013WR014458.

Davies, K., Doolan, C., Honert, R. van den, Shi, R., 2014. Water-saving impacts of smart meter technology: an empirical 5 year, whole-of-community study in Sydney, Australia. Water Resour. Res. 50, 7348-58. doi:10.1002/2014WR015812.

Doolan, C., 2010. Smart metering residential project 2008-2010. Sydney Water. Parramatta, NSW.

Erickson, T., Podlaseck, M.E., Sahu, S., Dai, J.D., Chao, T., Naphade, M., 2012. The Dubuque Water Portal: evaluation of the uptake, use and impact of residential water consumption feedback, in: CHI 2012, May 5-10, 2012, Austin Texas, USA. ACM, pp. 675-684. 
Fielding, K.S., Spinks, A., Russell, S., McCrea, R., Stewart, R., Gardner, J., 2013. An experimental test of voluntary strategies to promote urban water demand management. J. Environ. Manage. 114, 343-351. doi:10.1016/j.jenvman.2012.10.027.

Ganhao, A., Ribeiro, R., Tompkins, J., Kossieris, P., Mansfiled, L., 2015. iWIDGET Newsletter. http://www.iwidget.eu/images/pdf/IWIDGET_Newsletter_Issue_3.pdf (accessed 12.1.15).

Giurco, D., White, S., Stewart, R., 2010. Smart metering and water end-use data: conservation benefits and privacy risks. Water 2, 461-467. doi:10.3390/w2030461.

Granger, W., Yolles, P., 2014. Behavioural Water Efficiency = Power to Nudge. WaterSmart Innov. https://watersmartinnovations.com/documents/sessions/2014/2014-W-1429.pdf (accessed 12.1.15).

Hill, T., 2015. Data: The agent of change for the water industry, in: Towards the Digital Water Utility Conference. Melbourne, pp. 1-17.

Liu, A., Giurco, D., Mukheibir, P., (in press). Advancing household water-use feedback to inform customer behaviour for sustainable urban water. Water Sci. Technol. doi:102166/ws.2016.119.

Liu, A., Giurco, D., Mukheibir, P., 2016. Urban water conservation through customised water and end-use information. J. Clean. Prod. 112, 3164-3175. doi:10.1016/j.jclepro.2015.10.002.

Liu, A., Giurco, D., Mukheibir, P., 2015. Motivating metrics for household water-use feedback. Resour. Conserv. Recycl. 103, 29-46. doi:10.1016/j.resconrec.2015.05.008.

Liu, A., Giurco, D., Mukheibir, P., 2014. Online household water portal: User interactions and perceptions of water use, in: Book of Abstracts, 2014 SWGIC, Smart Water Grid International Conference, 25-27 November, 2014. Incheon, South Korea, pp. 102-8.

Liu, A., Giurco, D., Mukheibir, P., Watkins, G., 2013. Smart metering and billing: information to guide household water consumption. Water J. Aust. Water Assoc. 40, 73-77.

Mackay Regional Council, 2015. MiWater manage the Flow of Your H2O. Mackay Reg. Counc. http://www.mackay.qld.gov.au (accessed 7.1.15).

Makropoulos, C., Kossieris, P., Kozanis, S., Katsiri, E., Vamvakeridou-Lyroudia, L., 2014. From smart meters to smart decisions: web-based support for the water efficient household, in: 11th International Conference on Hydroinformatics, HIC 2014. New York City, pp. 1-8.

Morris, M.R., Teevan, J., 2009. Collaborative Web Search: Who, What, Where, When, and Why, Synthesis Lectures on Information Concepts, Retrieval, and Services. Morgan \& Claypool. doi:10.2200/S00230ED1V01Y200912ICR014

Naphade, M., 2011. Smart Water Pilot Study Report, IBM Research. Dubuque.

Neptune Technology Group, 2015. Smart Water Survey Report 2015. http://etsinsights.com/reports/u-ssmart-water-utility-report-2015/ (accessed 12.1.15).

Petersen, J.E., Shunturov, V., Janda, K., Platt, G., Weinberger, K., Corfas, R., Dennis, L., Derry, R., Epstein, C., Grossman, J., 2007. Dormitory residents reduce electricity consumption when exposed to real-time visual feedback and incentives. Int. J. Sustain. High. Educ. 8, 16-33. doi:10.1108/14676370710717562.

Profile.ID, 2011a. Hawks Nest - Tea Gardens: Population, dwellings and ethnicity. Community profile. http://profile.id.com.au/great-lakes/population?WebID=220 (accessed 5.18.16).

Profile.ID, 2011b. Greater Taree: Population, dwellings and ethnicity. Community profile. 
http://profile.id.com.au/greater-taree/population (accessed 5.18.16).

Sherrod, L.R., Flanagan, C., Youniss, J., 2002. Dimensions of citizenship and opportunities for youth development: The What, Why, When, Where, and Who of citizen development. Appl. Dev. Sci. 6, 264272. doi:10.1207/S1532480XADS0604.

Turner, A., Retamal, M., White, S., Palfreeman, L., Panikkar, A., 2010. Third Party Evaluation of Wide Bay Water Corporation Smart Metering. Report prepared by the Snowy Mountains Engineering Corporation and the Institute for Sustainable Futures, UTS, for the Department of the Environment, Water, Heritage and the Arts, Canberra.

WaterSmart, 2014. Powering Leak Alerts with AMI. WaterSmart Softw.

http://www.watersmart.com/partner-story/park-city-utah-leveraging-ami-real-time-leak-alerts/ (accessed 1.10.16).

Wetherall, B., 2008. Final report of the Eco-Pioneer pilot program. South East Water. Heatherton.

Young, R., Mackres, E., 2013. Tackling the Nexus: Exemplary Programs that Save Both Energy and Water. American Council for an Energy-Efficient Economy, Washington, D.C. 


\section{Appendix}

Table 1. Research studies and cases: practical considerations

\begin{tabular}{|c|c|c|c|c|c|c|c|c|c|c|c|c|c|c|c|c|c|c|c|c|}
\hline \multirow[b]{2}{*}{ Reference } & \multicolumn{8}{|l|}{ WHO } & \multicolumn{8}{|l|}{ WHAT } & \multirow{2}{*}{$\begin{array}{l}\text { WHY } \\
\\
\end{array}$} & \multicolumn{3}{|l|}{ WHEN } \\
\hline & 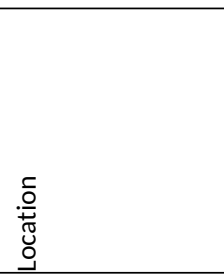 & 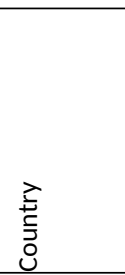 & $\begin{array}{l}\frac{n}{0} \\
\frac{0}{0} \\
\frac{0}{0} \\
\dddot{y} \\
\text { 오 }\end{array}$ & $\begin{array}{l}\frac{n}{0} \\
\stackrel{+}{0} \\
0\end{array}$ & 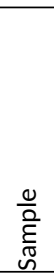 & $\begin{array}{l}\frac{.}{0} \\
\frac{0}{0} \\
\frac{\pi}{3} \\
\frac{0}{0} \\
2\end{array}$ & $\begin{array}{l}\frac{.5}{1} \\
\frac{0}{0}\end{array}$ & $\begin{array}{l}\text { 范 } \\
\frac{1}{0} \\
0\end{array}$ & $\begin{array}{l}\varepsilon \\
\frac{\xi}{\bar{\Xi}} \\
\frac{\Phi}{\Sigma}\end{array}$ & 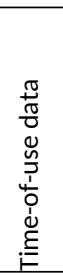 & $\begin{array}{l}\frac{\pi}{0} \\
\frac{\pi}{0} \\
0 \\
0 \\
\frac{y}{1} \\
\frac{1}{0} \\
\tilde{W}\end{array}$ & 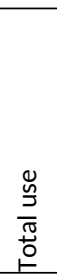 & 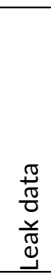 & 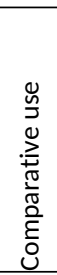 & 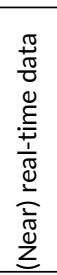 & $\begin{array}{l}\frac{\pi}{0} \\
\frac{\pi}{0} \\
\frac{0}{0} \\
\frac{0}{\pi} \\
\frac{\pi}{0}\end{array}$ & & 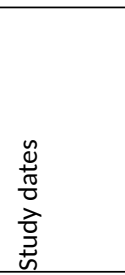 & 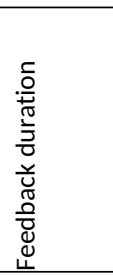 & 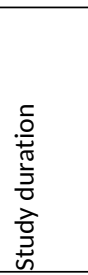 \\
\hline $\begin{array}{l}\text { Sydney Water } \\
\text { (Davies et al., } \\
\text { 2014) } \\
\end{array}$ & Westleigh, NSW & Australia & 82 & 82 & $\mathrm{x}$ & & $x$ & & IHD & $x$ & & $\mathrm{x}$ & $x$ & $x$ & $x$ & & $x$ & $\begin{array}{l}\text { Jun } 08 \text { - } \\
\text { Sep } 13\end{array}$ & $14 \mathrm{mths}$ & $\begin{array}{l}5 \mathrm{yr} \\
\text { follow- } \\
\text { up }\end{array}$ \\
\hline $\begin{array}{l}\text { (Fielding et al., } \\
\text { 2013) }\end{array}$ & $\begin{array}{l}\text { Brisbane, Ipswich, } \\
\text { Sunshine Coast \& } \\
\text { Gold Coast, QLD }\end{array}$ & Australia & $24+65+66$ & 66 & $\mathrm{x}$ & & $\mathrm{X}$ & & Postcards & & $\mathrm{x}$ & $x$ & $\mathrm{x}$ & $\mathrm{x}$ & & $\mathrm{X}$ & $x$ & $\begin{array}{l}\text { Jun } 10- \\
\text { Sep } 11\end{array}$ & $5 \mathrm{mths}$ & $1.3 \mathrm{yrs}$ \\
\hline $\begin{array}{l}\text { Water } \\
\text { Corporation } \\
\text { (Anda et al., } \\
\text { 2013) }\end{array}$ & Perth, WA & Australia & 12,256 & - & $x$ & $x$ & $x$ & & $\begin{array}{l}\text { Letters and } \\
\text { phone calls }\end{array}$ & & & $x$ & & $x$ & & $\mathrm{X}$ & $x$ & $\begin{array}{l}\text { Jul } 11- \\
\text { Aug } 12\end{array}$ & - & $1 \mathrm{yr}$ \\
\hline $\begin{array}{l}\text { Water } \\
\text { Corporation } \\
\text { (Anda et al., } \\
\text { 2013) }\end{array}$ & Perth, WA & Australia & 10 & - & $x$ & $x$ & $x$ & & $\begin{array}{l}\text { Portal \& } \\
\text { phone calls }\end{array}$ & $x$ & & $x$ & & $\mathrm{x}$ & $x$ & & $\mathrm{x}$ & $\begin{array}{l}\text { Feb-May } \\
12\end{array}$ & $1 \mathrm{mth}$ & $2 \mathrm{mths}$ \\
\hline $\begin{array}{l}\text { City of Dubuque } \\
\text { (Erickson et al., } \\
\text { 2012; Naphade } \\
\text { et. al. 2011). }\end{array}$ & Dubuque, CO & US & 151 & 152 & $x$ & & $x$ & & $\begin{array}{l}\text { Online } \\
\text { portal }\end{array}$ & $x$ & & $x$ & $x$ & $x$ & $x$ & & $x$ & $\begin{array}{l}\text { Sep - Dec } \\
10\end{array}$ & 15 wks & $\begin{array}{l}9+6 \\
\text { weeks }\end{array}$ \\
\hline $\begin{array}{l}\text { Sydney Water } \\
\text { (Doolan, 2010) }\end{array}$ & Westleigh, NSW & Australia & 161 & 20 & $x$ & & $\mathrm{X}$ & & $\mathrm{IHD}$ & $\mathrm{X}$ & & $x$ & $\mathrm{X}$ & $\mathrm{x}$ & $x$ & & $x$ & $\begin{array}{l}\text { Dec } 08 \text { - } \\
\text { Jun } 10\end{array}$ & $1 \mathrm{yr}$ & $1.5 \mathrm{yrs}$ \\
\hline $\begin{array}{l}\text { Wide Bay Water } \\
\text { Corporation } \\
\text { (Britton et al., } \\
\text { 2013) }\end{array}$ & Hervey Bay, QLD & Australia & $332+40$ & 100 & $x$ & & & & Letters & $x$ & & & $x$ & & & $x$ & $\mathrm{x}$ & $\begin{array}{l}\text { Jun } 08 \text { - } \\
\text { Jun } 09\end{array}$ & 3 mths & $1 \mathrm{yr}$ \\
\hline
\end{tabular}




\begin{tabular}{|c|c|c|c|c|c|c|c|c|c|c|c|c|c|c|c|c|c|c|c|}
\hline $\begin{array}{l}\text { South East } \\
\text { Water } \\
\text { (Wetherall, } \\
\text { 2008) }\end{array}$ & Melbourne, VIC & Australia & 50 & - & $x$ & & $x$ & $\begin{array}{l}\text { IHD \& } \\
\text { website }\end{array}$ & $x$ & & $\mathrm{x}$ & & & $\mathrm{x}$ & & $\mathrm{x}$ & $\begin{array}{l}\text { Apr } 07- \\
\text { Mar } 08\end{array}$ & Mar 07 & $1 \mathrm{yr}$ \\
\hline $\begin{array}{l}\text { (Petersen et al., } \\
\text { 2007) }\end{array}$ & Oberlin, $\mathrm{OH}$ & US & $\begin{array}{l}18 \\
\text { (dormitories) }\end{array}$ & - & - & & & Portal & $\mathrm{X}$ & & $\mathrm{X}$ & & $x$ & $x$ & & $x$ & $\begin{array}{l}\text { Feb } 05- \\
\text { Apr } 05\end{array}$ & $2 \mathrm{wks}$ & $3 \mathrm{mths}$ \\
\hline $\begin{array}{l}\text { MidCoast Water } \\
\text { (HWU study) } \\
\text { (Liu et al., 2016, } \\
\text { 2015) }\end{array}$ & $\begin{array}{l}\text { Tea } \\
\text { Gardens/Hawks } \\
\text { Nest, NSW }\end{array}$ & Australia & 34 & 34 & $x$ & & $x$ & $\begin{array}{l}\text { Paper } \\
\text { reports }\end{array}$ & & $\mathrm{X}$ & $\mathrm{x}$ & $x$ & $x$ & & $\mathrm{X}$ & $x$ & $\begin{array}{l}\text { Jun } 12- \\
\text { Jan } 14\end{array}$ & $4 \mathrm{mths}$ & $1.5 \mathrm{yrs}$ \\
\hline $\begin{array}{l}\text { MidCoast Water } \\
\text { (MHOW study) } \\
\text { (Liu et al., 2014, } \\
\text { in press) }\end{array}$ & $\begin{array}{l}\text { Greater Taree, } \\
\text { NSW }\end{array}$ & Australia & 60 & 60 & $x$ & & $x$ & Portal & $x$ & & $x$ & $x$ & $x$ & $x$ & & $x$ & $\begin{array}{l}\operatorname{Jan} 13- \\
\operatorname{Jan} 15\end{array}$ & $1 \mathrm{yr}$ & 2 yrs \\
\hline $\begin{array}{l}\text { Townsville City } \\
\text { Council }\end{array}$ & Townsville, QLD & Australia & 200 & - & $x$ & & $x$ & Portal & $x$ & & $\mathrm{x}$ & $x$ & $x$ & $\mathrm{x}$ & & $x$ & 2013 & $6 \mathrm{mths}$ & - \\
\hline $\begin{array}{l}\text { Mackay } \\
\text { Regional } \\
\text { Council (Mackay } \\
\text { Regional } \\
\text { Council, 2015) }\end{array}$ & Mackay, QLD & Australia & 36,000 & - & & $x$ & $x$ & Portal & $x$ & & $x$ & $x$ & $x$ & $x$ & & $x$ & $\begin{array}{l}\text { From } \\
2013 \\
\text { onwards }\end{array}$ & - & - \\
\hline $\begin{array}{l}\text { Global Water } \\
\text { Fathom U2You } \\
\text { (Hill, 2015) }\end{array}$ & Various & US & - & & & $x$ & $x$ & $\begin{array}{l}\text { Portal \& } \\
\text { smartphone } \\
\text { app }\end{array}$ & $x$ & & $x$ & $x$ & $x$ & $x$ & & $x$ & $\begin{array}{l}\text { From } \\
2011\end{array}$ & - & - \\
\hline $\begin{array}{l}\text { WaterSmart } \\
\text { (WaterSmart, } \\
\text { 2014) }\end{array}$ & Park City, Utah & US & 4,200 & - & $\mathrm{x}$ & $\mathrm{X}$ & & $\begin{array}{l}\text { Portal \& } \\
\text { paper or } \\
\text { email } \\
\text { reports }\end{array}$ & & & & & $x$ & & & $x$ & $\begin{array}{l}\text { From } \\
\text { May } \\
2014\end{array}$ & - & - \\
\hline $\begin{array}{l}\text { WaterSmart } \\
\text { (Granger and } \\
\text { Yolles, 2014) }\end{array}$ & Sacramento & US & 5,000 & 6,400 & & & & $\begin{array}{l}\text { Reports \& } \\
\text { portal }\end{array}$ & $x$ & 0 & $x$ & $\mathrm{X}$ & $x$ & $x$ & & $x$ & $\begin{array}{l}\text { Sep } 13- \\
\text { Aug } 14\end{array}$ & - & $6 \mathrm{mths}$ \\
\hline $\begin{array}{l}\text { iWIDGET } \\
\text { (Ganhao et al., } \\
\text { 2015) }\end{array}$ & $\begin{array}{l}\text { S. England, } \\
\text { Barcelos, } \\
\text { Athens }\end{array}$ & $\begin{array}{l}\text { UK, } \\
\text { Portugal } \\
\text { Greece }\end{array}$ & $\begin{array}{l}650 \\
86 \\
20\end{array}$ & $\begin{array}{l}650 \\
-\end{array}$ & $x$ & & $x$ & Portal & $x$ & & $\mathrm{x}$ & & $\mathrm{x}$ & & & $\mathrm{x}$ & $\begin{array}{l}2012- \\
2015\end{array}$ & $1 \mathrm{yr}$ & 3 yrs \\
\hline
\end{tabular}

Table notes: "X" Feature provided. "O" means estimate only. 
Table 2. Research studies and cases: strategic and evaluative considerations.

\begin{tabular}{|c|c|c|c|c|c|c|c|c|c|c|c|c|c|c|c|c|c|c|c|}
\hline \multirow[b]{2}{*}{ Reference } & \multirow{2}{*}{ 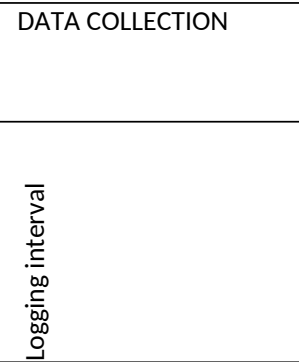 } & \multicolumn{4}{|c|}{ ANALYSIS } & \multicolumn{3}{|c|}{$\begin{array}{l}\text { KNOWLEDGE } \\
\text { SHARING }\end{array}$} & \multicolumn{2}{|c|}{ THEORY OF CHANGE } & \multicolumn{2}{|c|}{ RESOURCES } & \multicolumn{5}{|c|}{ TACTIC } & \multicolumn{2}{|c|}{ TECHNOLOGY } \\
\hline & & 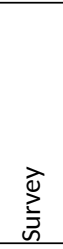 & 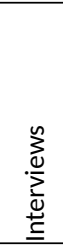 & $\sum_{\substack{n \\
0}}^{\substack{0 \\
0}}$ & 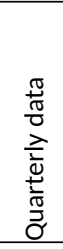 & $\begin{array}{l}\bar{\sigma} \\
\stackrel{\overline{5}}{0} \\
\text { 으 }\end{array}$ & $\begin{array}{l}\mathrm{T} \\
\stackrel{0}{Q} \\
\mathscr{Q}\end{array}$ & 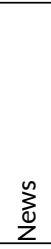 & 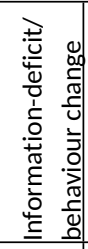 & 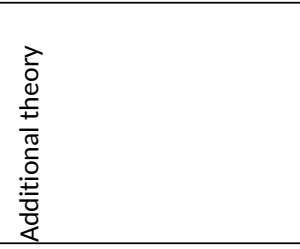 & 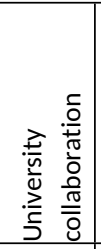 & 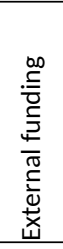 & 疍 & 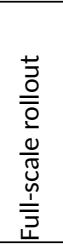 & 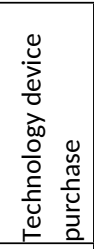 & 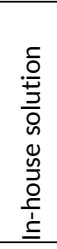 & 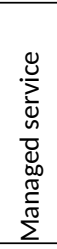 & $\sum_{<}^{\infty}$ & $\sum_{<}$ \\
\hline Sydney Water (Davies et al., 2014) & $\begin{array}{l}\text { Initially } 5 \mathrm{~min} \text {, } \\
\text { increasing up to } 60 \mathrm{~min}\end{array}$ & & & $\mathrm{x}$ & & $\mathrm{x}$ & & & $\mathrm{x}$ & & & & $\mathrm{x}$ & & $\mathrm{x}$ & & & $\mathrm{x}$ & \\
\hline (Fielding et al., 2013) & $5 \mathrm{~s}$ & & & $\mathrm{x}$ & & $x$ & $x$ & & $x$ & $\begin{array}{l}\text { Social norms, detailed } \\
\text { end-use }\end{array}$ & $x$ & $x$ & $\mathrm{x}$ & & & $x$ & & & \\
\hline Water Corporation (Anda et al., 2013) & $60 \mathrm{~min}$ & & & & & $x$ & & & & $\begin{array}{l}\text { Community Based Social } \\
\text { Marketing }\end{array}$ & & & & & & $x$ & & & \\
\hline Water Corporation (Anda et al., 2013) & $5 \min$ & & & & & $x$ & & & & & & & $x$ & & & $x$ & & & \\
\hline $\begin{array}{l}\text { City of Dubuque (Erickson et al., 2012; } \\
\text { Naphade et. al. 2011). }\end{array}$ & $15 \mathrm{~min}$ & $x$ & $\mathrm{X}$ & $\mathrm{x}$ & & $\mathrm{x}$ & $\mathrm{x}$ & & & & & & $\mathrm{x}$ & & & & $\mathrm{x}$ & $x$ & \\
\hline Sydney Water (Doolan, 2010) & $\begin{array}{l}5 \text { min; later up to } 60 \\
\min \end{array}$ & $\mathrm{x}$ & $x$ & $\mathrm{x}$ & & & $\mathrm{x}$ & & & & & & $\mathrm{x}$ & & $x$ & & & $\mathrm{x}$ & \\
\hline $\begin{array}{l}\text { Wide Bay Water Corporation (Britton } \\
\text { et al., 2013) }\end{array}$ & 1 hour & $x$ & & $x$ & & $x$ & & & & & $\mathrm{X}$ & $\mathrm{X}$ & $x$ & & & $x$ & & & \\
\hline South East Water (Wetherall, 2008) & - & $x$ & & & $\mathrm{x}$ & & $\mathrm{x}$ & & $x$ & & & & $\mathrm{x}$ & & $\mathrm{x}$ & & & & \\
\hline (Petersen et al., 2007) & - & & & & & $\mathrm{x}$ & & & & & & & $x$ & & & & & & \\
\hline $\begin{array}{l}\text { MidCoast Water (HWU study) (Liu et } \\
\text { al., 2016, 2015) }\end{array}$ & $1 \mathrm{~min}$ & $x$ & $\mathrm{X}$ & & & $x$ & & & $x$ & $\begin{array}{l}\text { Detailed end-use; Social } \\
\text { norms }\end{array}$ & $x$ & $x$ & $x$ & & & $x$ & & & \\
\hline $\begin{array}{l}\text { MidCoast Water (MHOW study) (Liu et } \\
\text { al., 2014, in press) }\end{array}$ & $1-5 \min$ & $\mathrm{x}$ & & $\mathrm{x}$ & & $x$ & & & $\mathrm{x}$ & $\begin{array}{l}\text { Goal setting; social } \\
\text { norms }\end{array}$ & $\mathrm{x}$ & $x$ & $x$ & & $x$ & $x$ & & $x$ & \\
\hline $\begin{array}{l}\text { Mackay Regional Council (Mackay } \\
\text { Regional Council, 2015) }\end{array}$ & I hour & & & & & & & & & & & & & $x$ & & $x$ & & & $x$ \\
\hline Global Water (Hill, 2015) & Various & & & & & & & & & & & & & $x$ & & & $x$ & & \\
\hline WaterSmart (Granger and Yolles, 2014) & Various & & & $\mathrm{x}$ & & & & & & Social norms & & $x$ & $x$ & $x$ & & & $\mathrm{x}$ & & $x$ \\
\hline iWIDGET (Ganhao et al., 2015) & & & & & & & & & & & & $\mathrm{X}$ & $x$ & & & & & & \\
\hline
\end{tabular}


Table 3 Research studies and cases: detailed overview of information content.

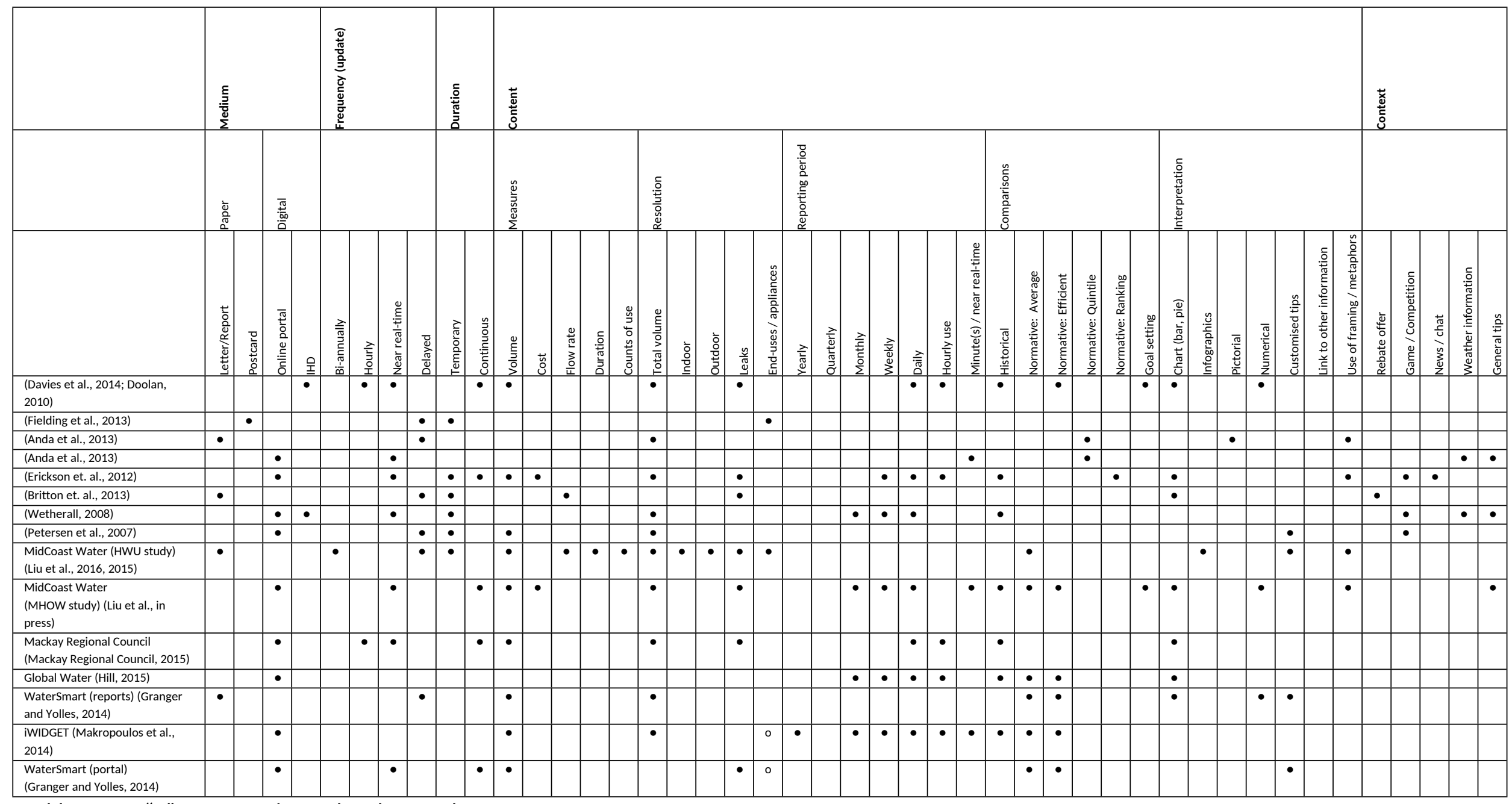

Table notes: "o" means estimated end-use only. 


\section{Research highlights}

- Smart metering presents new opportunities to engage householders about water use.

- Experiences from two household water-use feedback trials are structured.

- The literature on smart metering for water and feedback is reviewed.

- A program implementation framework for detailed water-use feedback is developed.

- Water utilities can target efforts that contribute to sustainable water usage. 